\title{
Oak Ridge National Laboratory Wireless Charging of Electric Vehicles - CRADA Report
}

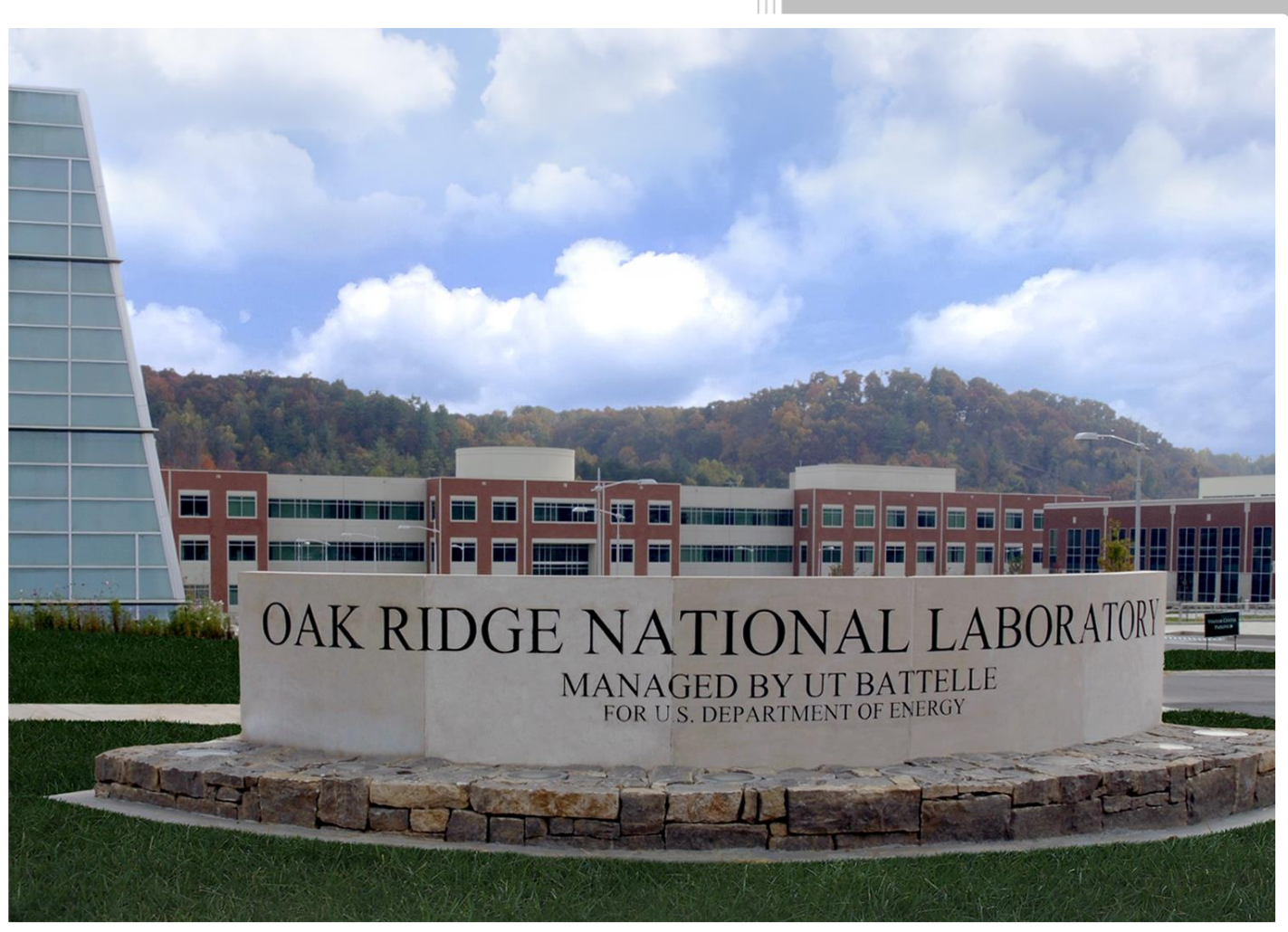

Approved for public release. Distribution is unlimited.
Omer C. Onar, Steven Campbell, Larry Seiber, Cliff White, Madhu Chinthavali, Lixin Tang, Paul Chambon, Burak Ozpineci, David E. Smith

$06 / 20 / 2016$ 


\section{DOCUMENT AVAILABILITY}

Reports produced after January 1, 1996, are generally available free via US Department of Energy (DOE) SciTech Connect.

Website http://www.osti.gov/scitech/

Reports produced before January 1, 1996, may be purchased by members of the public from the following source:

National Technical Information Service

5285 Port Royal Road

Springfield, VA 22161

Telephone 703-605-6000 (1-800-553-6847)

TDD 703-487-4639

Fax 703-605-6900

E-mail info@ntis.gov

Website http://www.ntis.gov/help/ordermethods.aspx

Reports are available to DOE employees, DOE contractors, Energy Technology Data Exchange representatives, and International Nuclear Information System representatives from the following source:

Office of Scientific and Technical Information

PO Box 62

Oak Ridge, TN 37831

Telephone 865-576-8401

Fax 865-576-5728

E-mail reports@osti.gov

Website http://www.osti.gov/contact.html

This report was prepared as an account of work sponsored by an agency of the United States Government. Neither the United States Government nor any agency thereof, nor any of their employees, makes any warranty, express or implied, or assumes any legal liability or responsibility for the accuracy, completeness, or usefulness of any information, apparatus, product, or process disclosed, or represents that its use would not infringe privately owned rights. Reference herein to any specific commercial product, process, or service by trade name, trademark, manufacturer, or otherwise, does not necessarily constitute or imply its endorsement, recommendation, or favoring by the United States Government or any agency thereof. The views and opinions of authors expressed herein do not necessarily state or reflect those of the United States Government or any agency thereof. 
Vehicle Systems Program

\title{
WIRELESS CHARGING OF ELECTRIC VEHICLES
}

Omer C. Onar, Steven Campbell, Larry Seiber, Cliff White, Madhu Chinthavali, Lixin Tang, Paul Chambon, and Burak Ozpineci

Power Electronics and Electric Machinery Group (PEEM)

Electrical and Electronics Systems Research Division (EESR)

David E. Smith,

Center for Transportation Analysis (CTA)

Vehicle Systems Research Group (VSR)

Energy and Transportation Science Division (ETSD)

Date Published: 06/20/2016

\author{
Prepared by \\ OAK RIDGE NATIONAL LABORATORY \\ Oak Ridge, Tennessee 37831-6283 \\ managed by \\ UT-BATTELLE, LLC \\ for the \\ US DEPARTMENT OF ENERGY \\ under contract DE-AC05-00OR22725
}

Approved for Public Release 


\section{Abstract}

Wireless power transfer (WPT) is a paradigm shift in electric-vehicle (EV) charging that offers the consumer an autonomous, safe, and convenient option to conductive charging and its attendant need for cables. With WPT, charging process can be fully automated due to the vehicle and grid side radio communication systems, and is non-contacting; therefore issues with leakage currents, ground faults, and touch potentials do not exist. It also eliminates the need for touching the heavy, bulky, dirty cables and plugs. It eliminates the fear of forgetting to plug-in and running out of charge the following day and eliminates the tripping hazards in public parking lots and in highly populated areas such as shopping malls, recreational areas, parking buildings, etc. Furthermore, the high-frequency magnetic fields employed in power transfer across a large air gap are focused and shielded, so that fringe fields (i.e., magnetic leakage/stray fields) attenuate rapidly over a transition region to levels well below limits set by international standards for the public zone (which starts at the perimeter of the vehicle and includes the passenger cabin). Oak Ridge National Laboratory's approach to WPT charging places strong emphasis on radio communications in the power regulation feedback channel augmented with software control algorithms. The over-arching goal for WPT is minimization of vehicle on-board complexity by keeping the secondary side content confined to coil tuning, rectification, filtering, and interfacing to the regenerative energy-storage system (RESS). This report summarizes the CRADA work between the Oak Ridge National Laboratory and the Toyota Research Institute of North America, Toyota Motor Engineering and Manufacturing North America (TEMA) on the wireless charging of electric vehicles which was funded by Department of Energy under DE-FOA-000667. In this project, ORNL is the lead agency and Toyota TEMA is one of the major partners. Over the course of the project, ORNL and Toyota TEMA worked closely on the vehicle integration plans, compatibility, and the interoperability of the wireless charging technology developed by ORNL for the vehicles manufactured by Toyota. These vehicles include a Toyota Prius Plugin Hybrid electric vehicle, a Scion iQ electric vehicle, and two Toyota RAV4 electric vehicles. The research include not only the hardware integration but also the controls and communication systems development to control and automate the charging process for these vehicles by utilizing a feedback channel from vehicle to the stationary unit for power regulation.

\section{Statement of Objectives}

The main objective of this project is to coordinate multi-party team for the design, development, and fabrication of WPT grid side unit (GSU), coupling coils, and the vehicle side power conditioning units. The GSU includes the active front-end rectifier with power factor correction (PFC), high-frequency power inverter, and the high-frequency isolation transformer whereas vehicle side unit includes a resonant tuning capacitor, a bridge rectifier, a filter circuit, and the additional relays and contactors that are used to timely respond to the charging request or to comply with the charging protocols that a vehicle may have (CHAdeMO, J1772, or direct battery connection). The objective of this work is to demonstrate a fully automated charging process including the alignment, start charging, stop charging, and the emergency and orderly shutdown procedures while meeting at least $6.6 \mathrm{~kW}$ power transfer over $160 \mathrm{~mm}$ magnetic airgap while exceeding an overall (end-to-end) efficiency of $85 \%$. After integrating ORNL developed WPT technology into demonstration 
vehicles, an additional objective was to validate the system operation in an independent testing laboratory (Idaho National Laboratory) for field testing of this technology which will assist in system improvements and standards development. In this project, Evatran was the commercialization partner and under ORNL guidance worked on cost and component optimization and fabrication of GSUs and also the primary and secondary coils. Evatran also worked on vehicle integrations in coordination with ORNL and other partners. Clemson University ICAR Center was the demonstration site for phase \#2 deliverables of the project. Clemson University, in collaboration with Cisco Systems, also supported the radio communications developments and radio integrations to the vehicles and the WPT equipment on the vehicles. Finally, Toyota Motor Corporation is the vehicle OEM partner provided the vehicles and collaborated with ORNL on the vehicle integrations. One last objective of this project was to demonstrate in-motion wireless charging on Toyota RAV4 vehicles to prove feasibility and collect data.

\section{Benefits to the Funding DOE Office's Mission}

The U.S. Department of Energy's Vehicle Technologies Office (VTO) supports research, development (R\&D), and deployment of efficient and sustainable highway transportation technologies that will improve fuel economy and enable America to use less petroleum. These technologies, which include plug-in electric vehicles (also known as PEVs or electric cars), batteries, electric drive technologies, advanced combustion engines, lightweight materials, and alternative fuels, will increase Americans' mobility and energy security, while lowering costs and reducing environmental impacts. DOE's VTO aims to reduce the cost of transportation, support the U.S. economy, improve our energy security, and protect the public health and the environment. From this perspective, wireless power transfer is recognized by a key enabling technology for the wide-spread adoption of electric vehicles since it eliminates one hurdle of electric vehicles; plugging-in. Wireless charging, when applied in dynamic or quasi-dynamic scenarios, also provides unlimited range to the electric vehicles and removes the range anxiety and long charging times since the vehicles can be continuously charged "on-the-go." With these features, WPT promotes and accelerates the transportation electrification efforts for a cost-effective, clean, efficient, and affordable transportation. A recent ORNL study ${ }^{1}$ revealed that the market share of plug-in EVs could increase up to $65 \%$ among the total light duty vehicle sales if $1 \%$ of the roadways were electrified with $60 \mathrm{~kW}$ dynamic wireless charging systems. Dynamic wireless charging will reduce the range anxiety and it would promote further deployment of electric vehicles which will in turns reduce the energy consumption since electric vehicles have higher energy (fuel) economies. This technology is also applicable for class 7-8 heavy duty vehicles. For instance, typical truck of that class burns approximately 1 gallon of diesel fuel for each hour that it idles. When used in port applications, this technology can eliminate 7.2 million gallons of diesel consumption and $35,605.6$ tons/year emissions ${ }^{2,3}$. This technology is also closely related to the lightweighting

${ }^{1}$ Z. Li, J. Li, and J. Dong, "Dynamic wireless power transfer: Potential impact on plug-in electric vehicle adoption," Society of Automotive Engineers Technical Paper, 2014-01-1965.

${ }^{2}$ T. A. Lopez, "Electric Truck Demonstration Project", The Port of Los Angeles, https://www.portoflosangeles.org/DOC/Electric Truck Fact Sheet.pdf

${ }^{3}$ Environmental Protection Agency (EPA), "What you should know about truck engine idling," https://www3.epa.gov/region1/eco/diesel/pdfs/Diesel Factsheet Truck Idling.pdf 
activities of the DOE Vehicle Technologies Office. For instance, a typical 40-feet city bus travelling 85 miles per day, would require $\sim 391 \mathrm{kWh}$ battery pack that weighs $1955 \mathrm{~kg}$. However, if equipped with wireless charging technology, it would be sufficient to have a $18.4 \mathrm{kWh}$ battery pack that would weigh only $92 \mathrm{~kg}$, which would also improve the fuel economy of the bus ${ }^{4}$. Lightweighting is also possible for light-duty passenger vehicles. Depending on the deployment scenarios, instead of a 100 mile range $\mathrm{EV}$, a 40 mile range $\mathrm{EV}$ could be used which would result in battery pack weight reduction of $220 \mathrm{lbs}(\sim 100 \mathrm{~kg})$.

\section{Technical Discussion of Work Performed by All Parties}

Wireless charging of electric vehicles has the potential to eclipse conductive chargers because of its flexibility and convenience to the customer. Use of private and secure radio communications, especially vehicle to infrastructure (V2I), and standardization means that any vehicle would be able to charge at any location. The wireless charging process can be totally transparent to the customer, which would increase the use of opportunity charging with the appropriate infrastructure. The goals and accomplishments of this project during the performance period covered several advancements and integrations in areas including coils, control systems, vehicle integrations, and the site preparations. Through this project, ORNL and partners developed a deep understanding of WPT, real vehicle implementations, control system design and communications for closed loop regulation of power transfer, and the design improvements for higher performance and cost effectiveness. During the course of this CRADA, hardware and software updates, technology developments, as well as the project strategies are coordinated with the partners.

During the phase \#2 of the FOA \#667 project, the team improved the overall operation of the active front-end rectifier with power factor correction, high-frequency power inverter, high-frequency isolation transformer, and the efficiency of the primary and secondary electromagnetic induction resonance coupling coils. Hardware and software developments completed and system is designed to be interoperable with five different vehicles with different charging protocols, target voltage, current, power levels, ramp rates, and response times. A single hardware is built to be interoperable with software changes for each different vehicle. At the end of phase \#2,6.6kW power transfer to Scion iQ EV with $>85 \%$ end-to-end efficiency while meeting the electric and electromagnetic field limits indicated in International Commission on Non-Ionizing Radiation Protection (ICNIRP); i.e., <6.25 $\mu \mathrm{T}$ and $<83 \mathrm{~V} / \mathrm{m}$ was demonstrated. In addition, team successfully demonstrated the wireless charging operation of both the Toyota Prius Plug-in and Scion iQ EV including the wireless communications, alignment system, charging initiation and ramping, full charging, and orderly and emergency shut down procedures.

The grid side unit operation and technical details of the vehicle integration plans are discussed below.

Grid Side Unit Operation: The function of the primary system is to take the AC power from a 208/240V AC supply and generate high frequency current to the primary coil for electromagnetic field generation. During this operation, the PFC gets the AC voltage from the grid, rectifies it while boosting and provides a regulated voltage to the inverter input. Inverter uses the input voltage provided by $\mathrm{PFC}$ and generates high frequency $\mathrm{AC}$ voltage to

\footnotetext{
${ }^{4}$ Chicago Transit Authority (CTA), "CTA Facts at a Glance," http://www.transitchicago.com/about/facts.aspx
} 
the primary coil. Evatran controller handles the alignment of the secondary coil to the primary coil and communicates to the vehicle side through the radios and commands to the slave digital signal processor (DSP) unit. The operation and normal or emergency shut down commands, reference secondary power or voltage commands are all communicated to the DSP through the Evatran control module. This operation is illustrated in Figure 1.

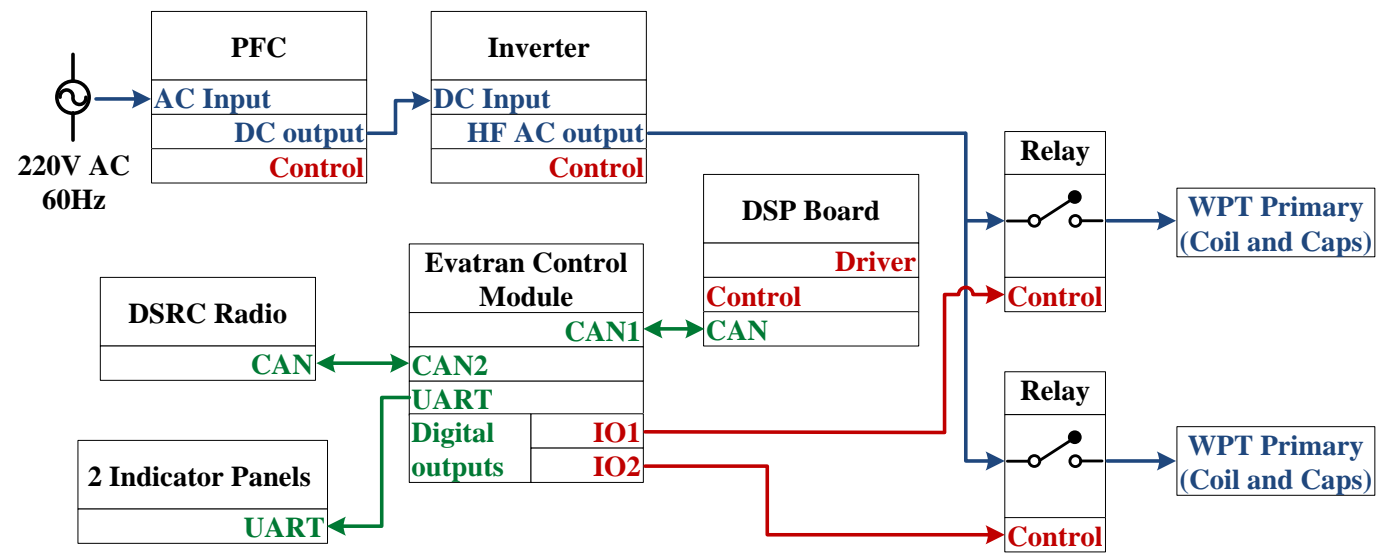

Figure 1. Grid side unit operational block diagram with Ebatran control module and ORNL DSP controller.

The grid side unit hardware development is shown in Figure 2 that includes the active frontend rectifier with power factor correction, high-frequency power inverter, and the highfrequency isolation transformer.

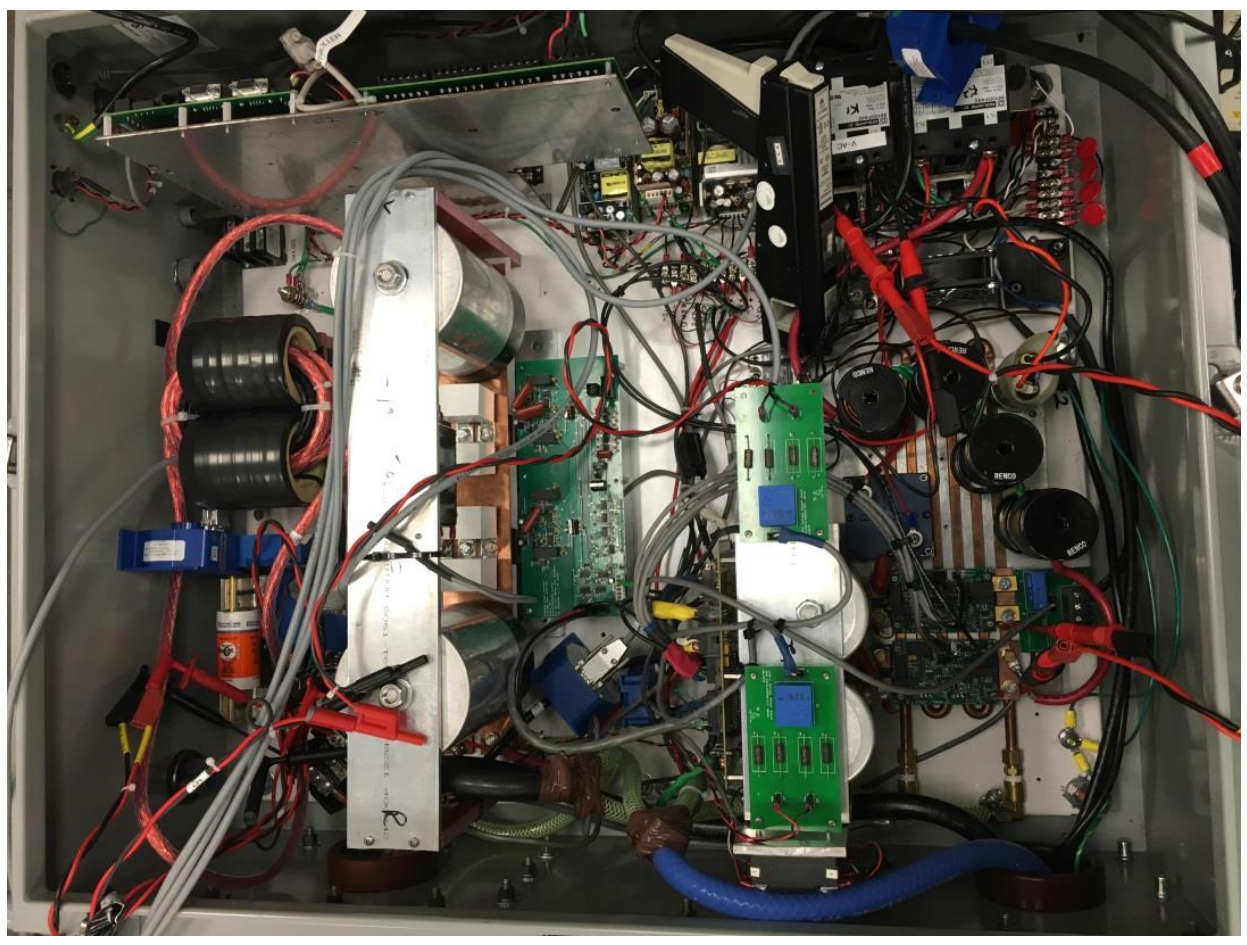

Figure 2. Grid side unit hardware. 
Electromagnetic Coupling Coils: The primary (transmit, stationary side) coil uses the high-freuency electric current to generate magnetic field that links to the secondary (receive, vehicle side) coil. Electromagnetic design of WPT coupling coils provides the most fundamental investigation into their performance. At ORNL the WPT team developed couplers based on the magnetic vector potential at a field point due to current flowing in an ideal primary coil conductor. The potential at this field point is defined to lie at the location of the secondary coil. For a coil pair of radius a, assuming infinitesimal conductor radius, and having a coil to coil spacing, $\mathrm{z}$, then the radius vector from the primary coil origin to the field point becomes $\mathrm{r}=\sqrt{\left(a^{2}+z^{2}\right)}$. The corresponding vector potential, $A_{\phi}$, for the case of $N_{l}$ primary turns and $I_{l}$ Amps yield a primary excitation of $N_{l} I_{l}$ amp-turns. This primary excitation is depicted as $I_{d l}$ in Figure 3 where $a_{1}=a_{2}=a$ for convenience.

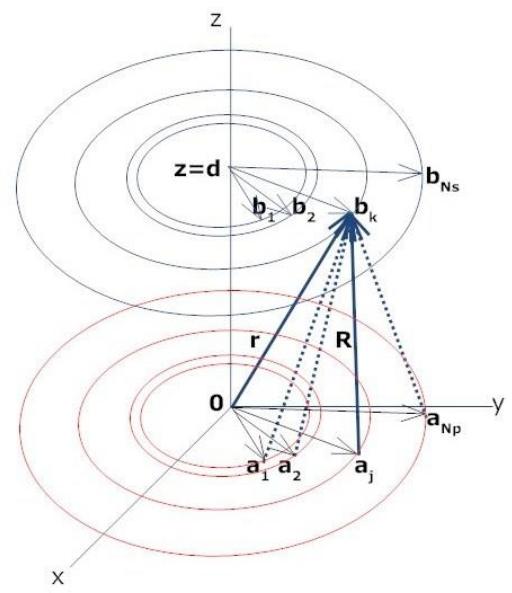

Figure 3. Analytical expression of vector potential for coupler design.

In coil design, first, the vector potential at each secondary coil turn is computed as the result of applied current in each of the primary coil turns. Flux linking the secondary coil is then the line integral of the vector potential at each turn which is then summed for total flux linkage. Them the sum of linkage is averaged. The ratio of flux linkage to the current finally results in the coil inductance. The sizing diagram and dimensions of the primary and secondary coil is provided in Figure 4.
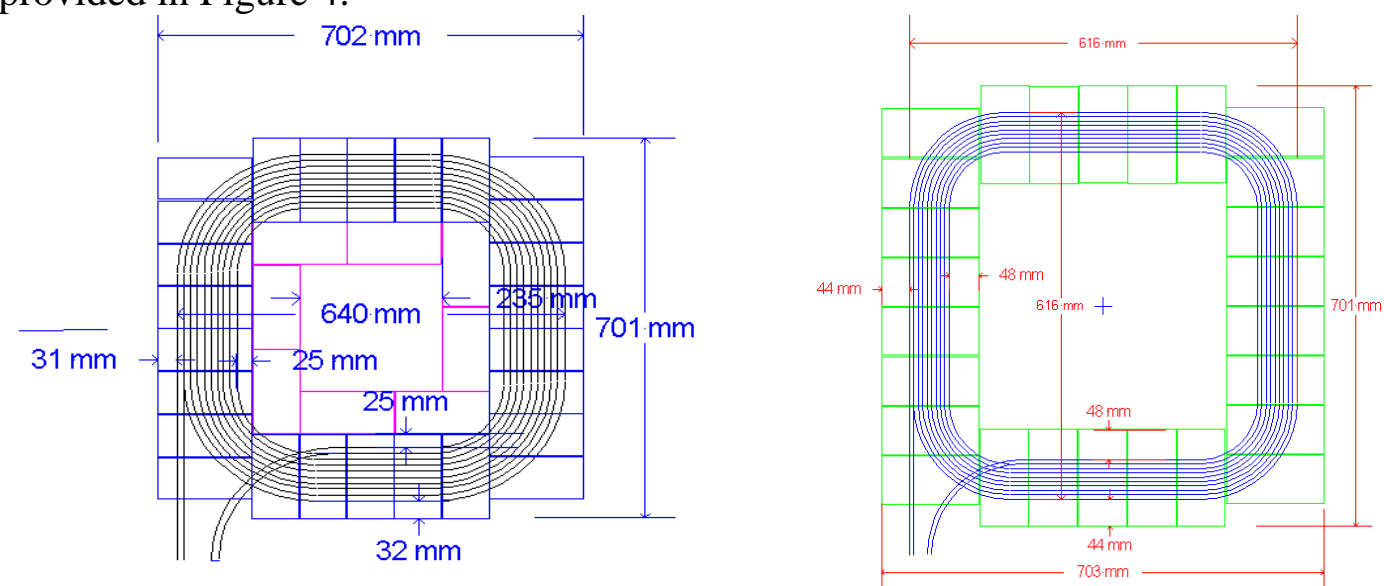

Figure 4. ORNL designed new primary (left) and secondary (right) coil design and dimensions. 
The picture of the new primary coil winding is presented in Figure 5.

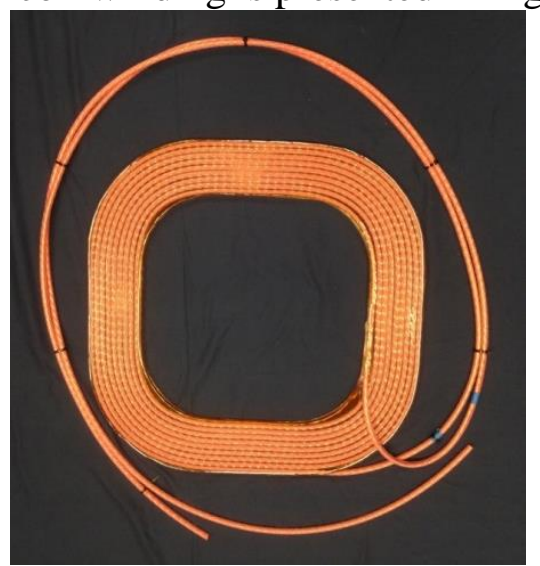

Figure 5. ORNL designed primary coil winding meeting the design requirements.

Primarily, the coils are designed to result in higher coupling factor at $\mathrm{z}=150 \mathrm{~mm}$ airgap as compared to the coils developed and built during the phase \#1. The analysis resulted in coupling $\mathrm{k}(\mathrm{z})=\sim 0.3$ at $150 \mathrm{~mm}$ airgap whereas the phase $\# 1$ coils had a coupling factor of $\mathrm{k}(\mathrm{z})=\sim 0.2$ at the same airgap. The higher coupling factor for the same coil separation distance results in reduced magnetizing current to the mutual inductance branch in the equivalent circuit; therefore, it reduces the reactive power needed from the inverter to magnetize the coils. This also reduces the primary coil losses as the reactive power oscillates from inverter DC link capacitors to the primary coil winding. The coupling factor variation of the new pair of coils as a function of the airgap is obtained as given in Figure 6 through a set of experimental results.

\section{k Value Comparison} FOA \#667 coils at $22 \mathrm{kHz}$

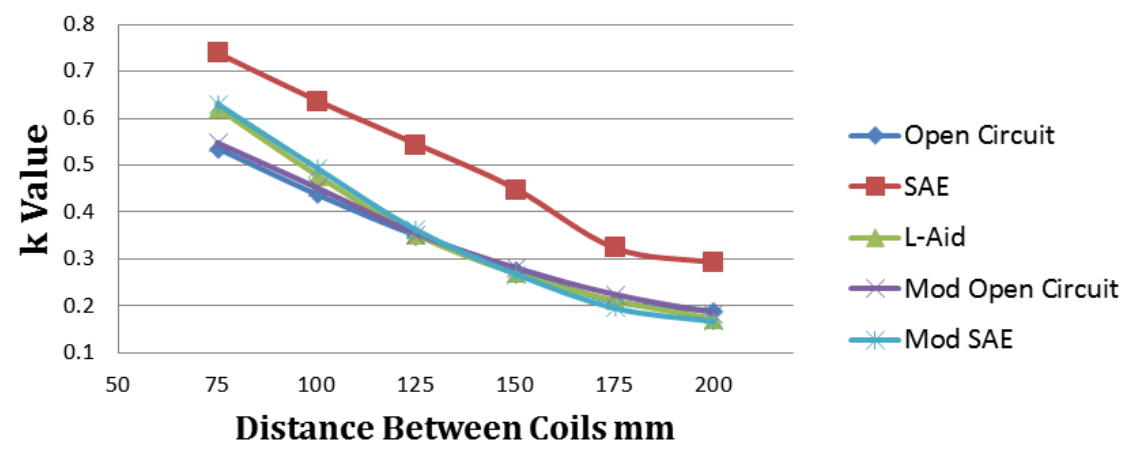

Figure 6. Coil performance characteristics: coupling factor variation at different airgaps.

In addition to the coupling factor, the winding $\mathrm{AC}$ resistance is also important since $\mathrm{AC}$ resistance of the Litz wire determines the Joule or copper losses. The iron losses of the coils are about $100 \mathrm{~W} /$ liter at $\mathrm{f}_{\mathrm{s}}=25 \mathrm{kHz}$ according to the $\mathrm{MnZn}$ ferrite material characteristics. The AC coil resistance as a function of the operating frequency is represented in Figure 7. 


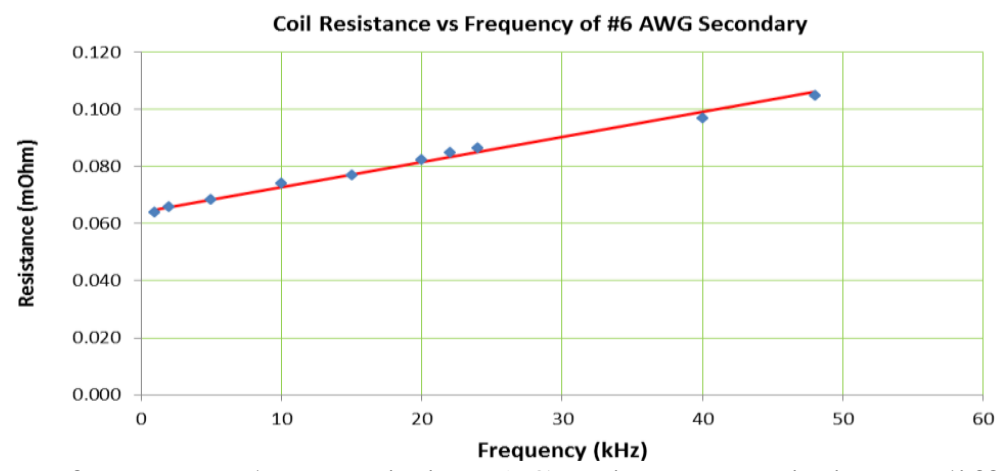

Figure 7. Coil performance characteristics: AC resistance variation at different operating frequencies.

The electrical parameters of the primary and secondary coils are provided in Table 1.

Table 1: Electrical parameters of the coils.

\begin{tabular}{|c|c|c|}
\hline $\begin{array}{c}\text { Inductance } \\
{[\mu \mathrm{H}]}\end{array}$ & $\begin{array}{c}\text { AC resistance } \\
{[\Omega](@ 22 \mathrm{kHz})}\end{array}$ & $\begin{array}{c}\mathrm{DC} \\
\text { resistance } \\
(\Omega)\end{array}$ \\
\hline $\mathrm{L}_{1}=115.79$ & $\mathrm{R}_{\mathrm{ACl}}=0.1227$ & $\mathrm{R}_{\mathrm{DCl}}=0.0121$ \\
\hline $\mathrm{L}_{2}=132.6$ & $\mathrm{R}_{\mathrm{AC} 2}=0.1508$ & $\mathrm{R}_{\mathrm{DC} 2}=0.0299$ \\
\hline
\end{tabular}

WPT Integration for Toyota Prius Plug-in with J1772 Charging Protocol: For the Prius Plug-in electric vehicle, the team needed to utilize the vehicle on-board charger (OBC), as required by Toyota. Based on the $\mathrm{OBC}$ restrictions, a secondary inverter is connected at the output of the vehicle side rectifier in order to generate $\mathrm{AC}$ voltage again for the $\mathrm{OBC}$. The selected inverter has a wide input range and its output voltage is regulated. In this mode of operation for the Prius, the control system utilizes a voltage regulation feedback control loop. The reference DC link voltage at the vehicle side is communicated to the DSP controller and DSP controller regulates the PFC output voltage at the grid side to accommodate this need. The block diagram of this operation is featured in Figure 8.

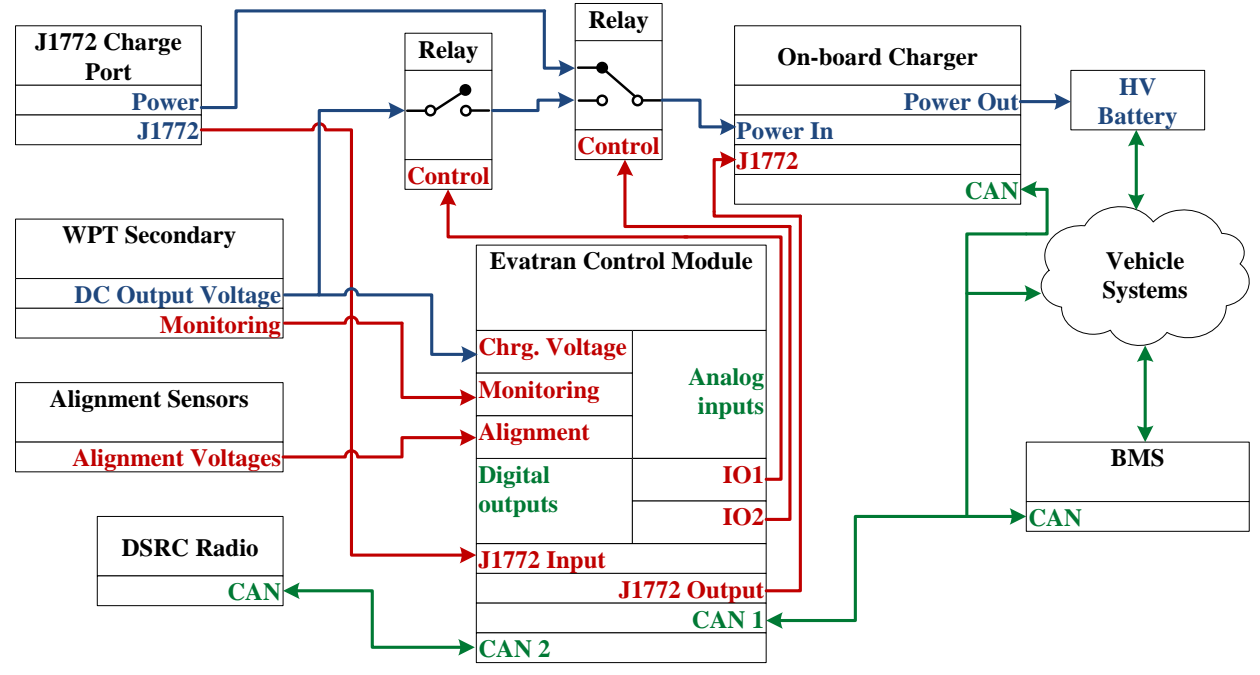

Figure 8. Operational block diagram of the wireless J1772 integration for Toyota Prius Plug-in hybrid electric vehicle. 
WPT Integration for Scion iQ EV with CHAdeMO charging protocol and Toyota RAV4 EV with direct battery connection: For the direct battery connection, which is featured for the add-on battery system of the modified Toyota Rav4 EV vehicle, a reference current is applied to the battery in current regulation mode while monitoring the battery maximum voltage limit. This mode of operation is illustrated in Figure 9. For Scion iQ, which required $\mathrm{CHAdeMO}$ charging protocol, additional relays and a minimum load resistor was utilized in order to timely respond to a charge request with a reference voltage applied to the CHAdeMO input connectors. WPT system also has to meet the ramp up time and current ripple amplitudes required by the CHAdemo protocol.

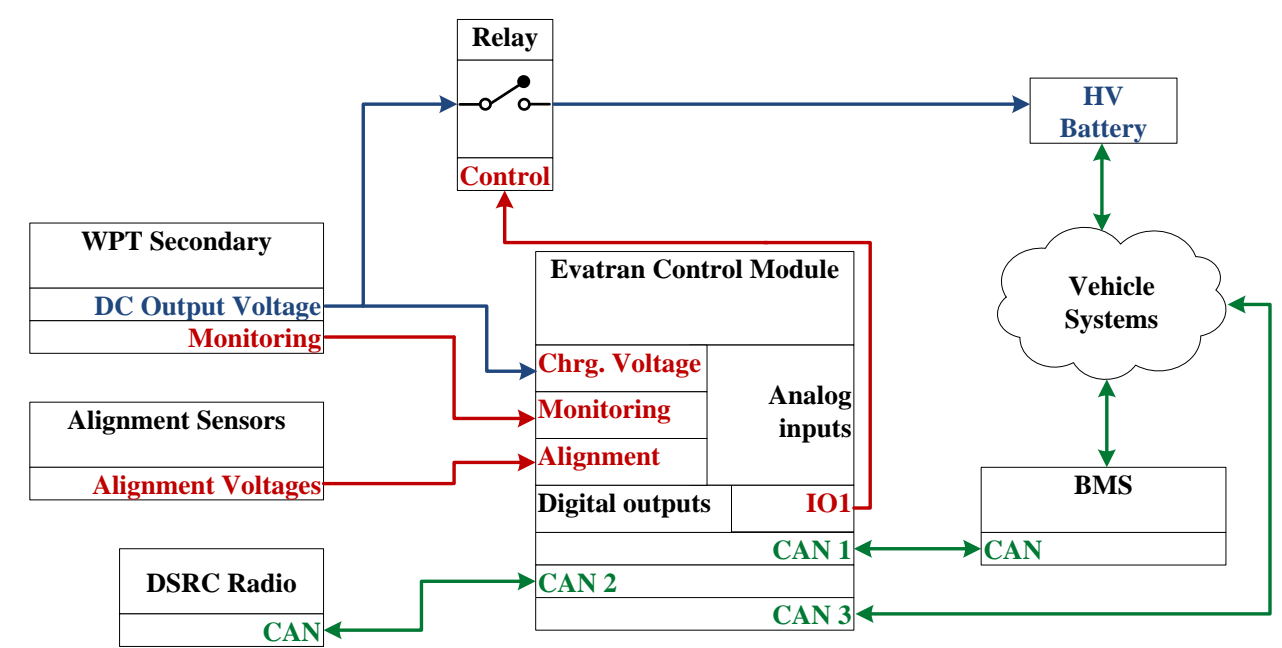

Figure 9. Operational block diagram for the direct battery or CHAdeMO connection of vehicle side WPT equipment.

The vehicle integration challenges are outlined below and summarized in Table 2:

1) Toyota Prius Plug-in: This vehicle requires integration through the vehicle side on-board charger (OBC). The Prius Plug-in OBC only works with regulated 208-240 Vrms AC voltage input with $50-60 \mathrm{~Hz}$ frequency. The nominal power rating of the Prius Plug-in $\mathrm{OBC}$ is $2.1 \mathrm{~kW}$ with a maximum of $2.5 \mathrm{~kW}$.

2) Scion iQ EV: Nominal battery voltage of this vehicle is $277 \mathrm{Vdc}$. This vehicle requires integration through CHAdeMO charging protocol with a predefined response time, current ramp rate, maximum current ripples, and the reference current tracking. For instance, once the charge request is received, the WPT system should respond in 1 second with a $10 \mathrm{~A} / \mathrm{s}$ ramp rate. Power transferred is up to $6.6 \mathrm{~kW}$.

3) Toyota RAV4 EV: This vehicle is equipped with $392.5 \mathrm{~V}$ (maximum), $11 \mathrm{kWh}$ add-on battery pack for WPT integration. Power rating is up to $28 \mathrm{~kW}$ ( $70 \mathrm{~A}$ maximum battery current). 
Table 2. Summary of vehicle integration specifications.

\begin{tabular}{l|l|l|l|}
\hline $\begin{array}{l}\text { Charging } \\
\text { protocol }\end{array}$ & J1772 OBC & CHAdeMO & Direct to battery \\
\hline $\begin{array}{l}\text { Vehicle input } \\
\text { side requirement }\end{array}$ & $\begin{array}{l}\text { No DC, only AC } \\
50 / 60 \mathrm{~Hz}\end{array}$ & $\begin{array}{l}\text { DC reference current } \\
\text { tracking with very fast, } \\
\text { specific current ramp } \\
\text { rates and response times }\end{array}$ & N/A \\
\hline $\begin{array}{l}\text { Vehicle input } \\
\text { voltage (DC) }\end{array}$ & N/A & Vdc>277V & Vdc $>350 \mathrm{~V}$ \\
\hline $\begin{array}{l}\text { Vehicle input } \\
\text { voltage (AC) }\end{array}$ & $208 / 220 / 240 \mathrm{Vac}$ & N/A & N/A \\
\hline $\begin{array}{l}\text { Rater power } \\
\text { Natius Plug-in }\end{array}$ & $2.1 \mathrm{~kW}$ & $\begin{array}{l}\text { 6.6kW to a nominal } \\
277 \mathrm{~V} \text { battery }\end{array}$ & $\begin{array}{l}\text { Scion IQ EV } \\
350 \mathrm{~V} \text { battery }\end{array}$ \\
\hline
\end{tabular}

In preparation for the phase \#2 demonstration events Grid-side Unit \#1 (GSU\#1) and the Toyota supplied Scion iQ, with the WPT system integrated by Evatran, were setup with appropriate power meters and sensors to provide measurements of the system's charging efficiency and power transfer rate as shown in Figure 10.

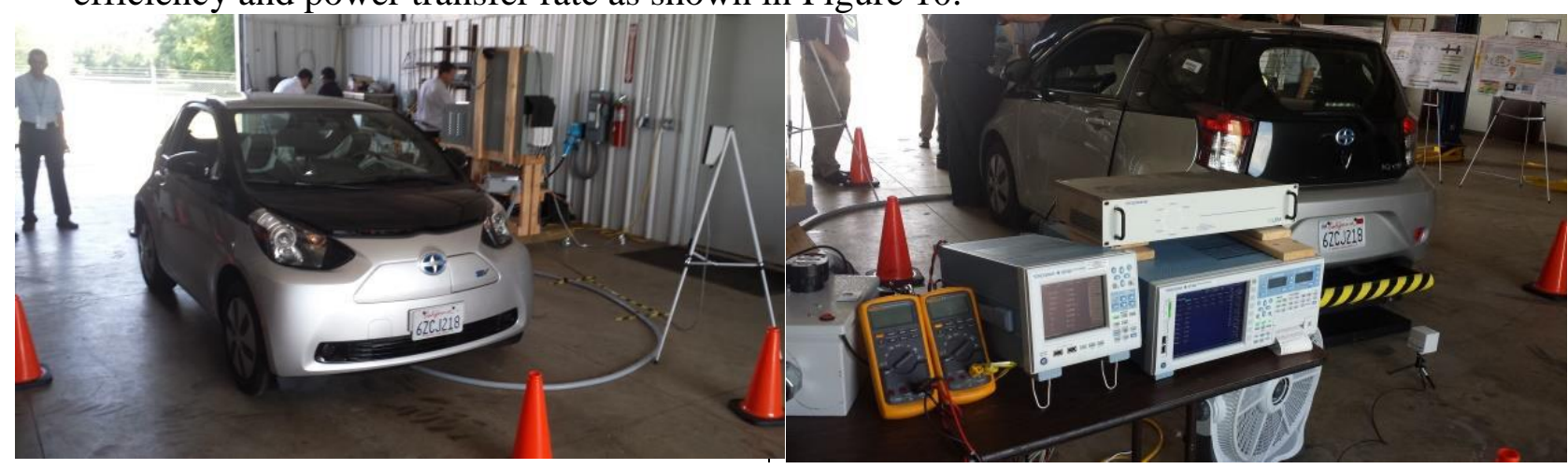

Figure 10. Scion iQ tests with efficiency measurement and power analyzer hardware.

During the tests, the system was able to charge the Scion iQ at $6.9 \mathrm{~kW}$ across a $165 \mathrm{~mm}$ air gap and obtain a $85.49 \%$ power transfer efficiency, as seen Figure 11. This exceeds the gateway power, efficiency and air gap requirements for the program. 

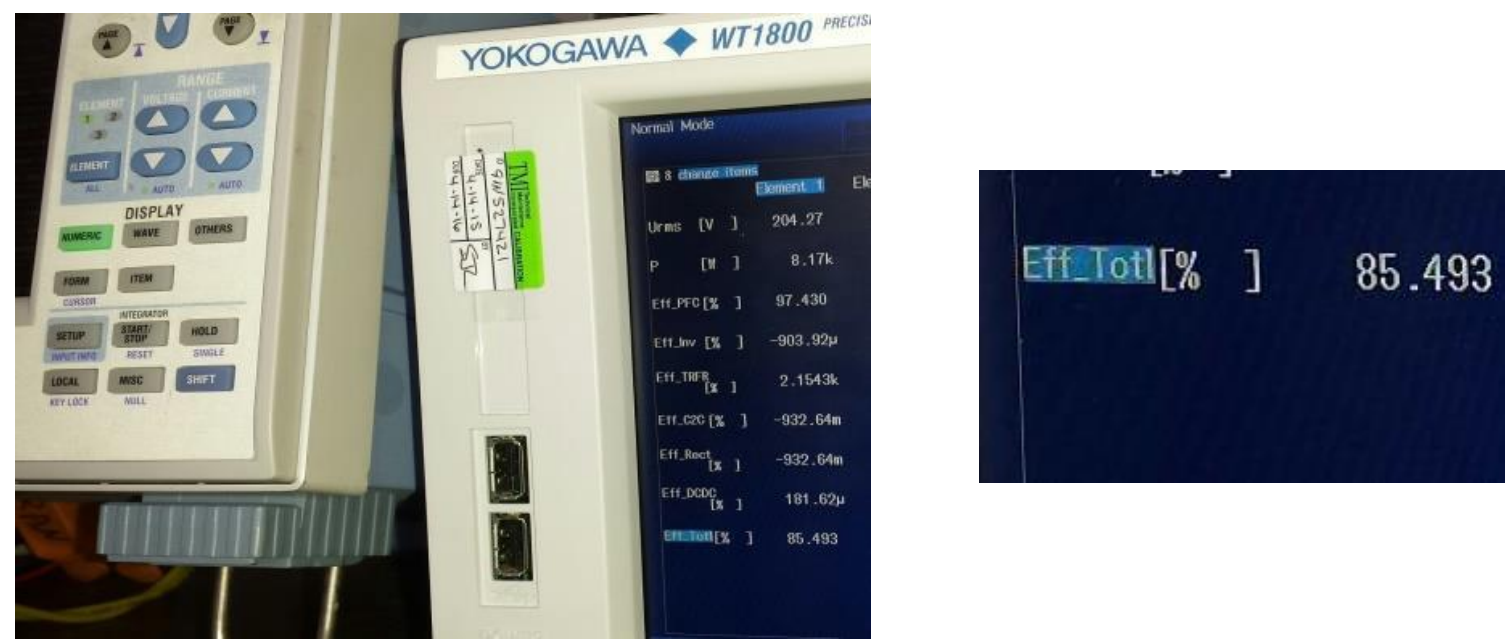

Figure 11. Power analyzer screens while charging the Scion iQ.

Prius Plug-in being wirelessly charged is shown in Figure 12.

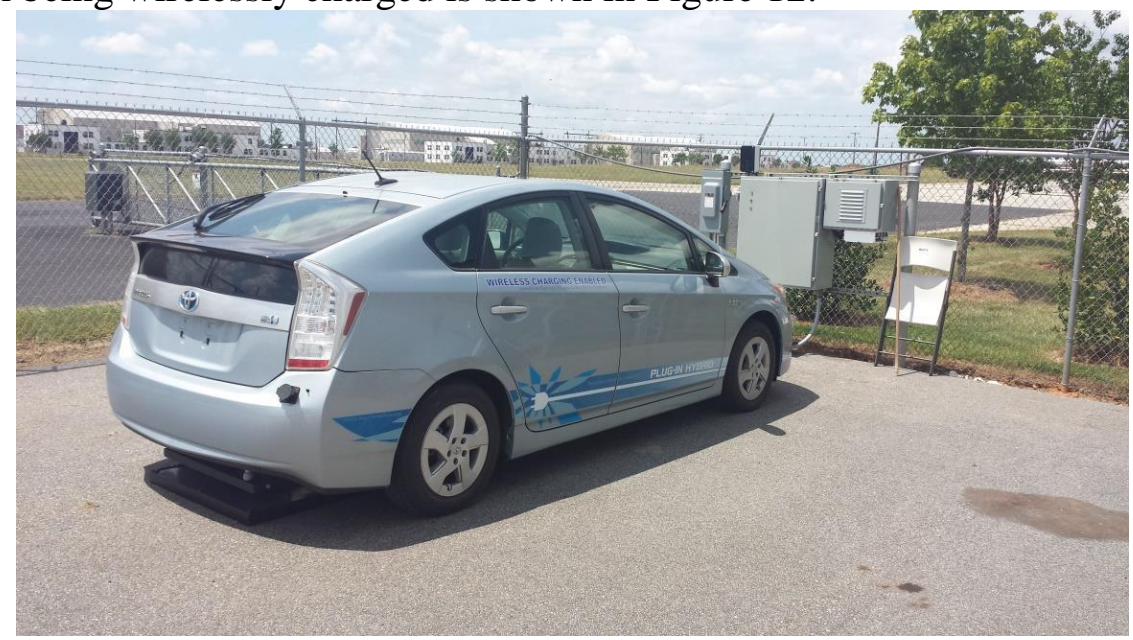

Figure 12. Wireless charging of a Plug-in Prius.

Toyota RAV4 wireless charging initial test results are also included as follows. At 162 $\mathrm{mm}$ airgap with $220 \mathrm{~V}$ AC input voltage, the power flow and efficiency across 5 power conversion stages with 6 input and output voltage and current pairs are presented in Figure 13. According to these results, active front-end rectifier with power factor correction, high frequency inverter, high frequency isolation transformer, primary and secondary coupling coils, and the vehicle side rectifier and filter efficiency recorded 97.41\%, 97.94\%, 97.05\%, $94.17 \%$, and $97.70 \%$. End-to-end efficiency of the system is recorded $85.18 \%$ whereas dc-todc efficiency from inverter input to the vehicle battery terminals resulted in $89.51 \%$. In order to deliver $6.6 \mathrm{~kW}$ power to the vehicle battery, $7.76 \mathrm{~kW}$ power is drawn from the utility grid. Voltage, current, active power $(\mathrm{P})$, reactive power $(\mathrm{Q})$, apparent power $(\mathrm{S})$, power factor $(\lambda)$, and the power angle $(\varphi)$ for all power conversions strategies, in addition to the primary coil voltage and the primary side tuning capacitor voltage are presented in Figure 14. Operational waveforms with expanded views for the high frequency elements (inverter, transformer, and the coils) are presented in Figure 15 whereas Figure 16 shows the operational waveforms for low frequency items (grid side AC input, DC link, and vehicle battery voltage and current). 


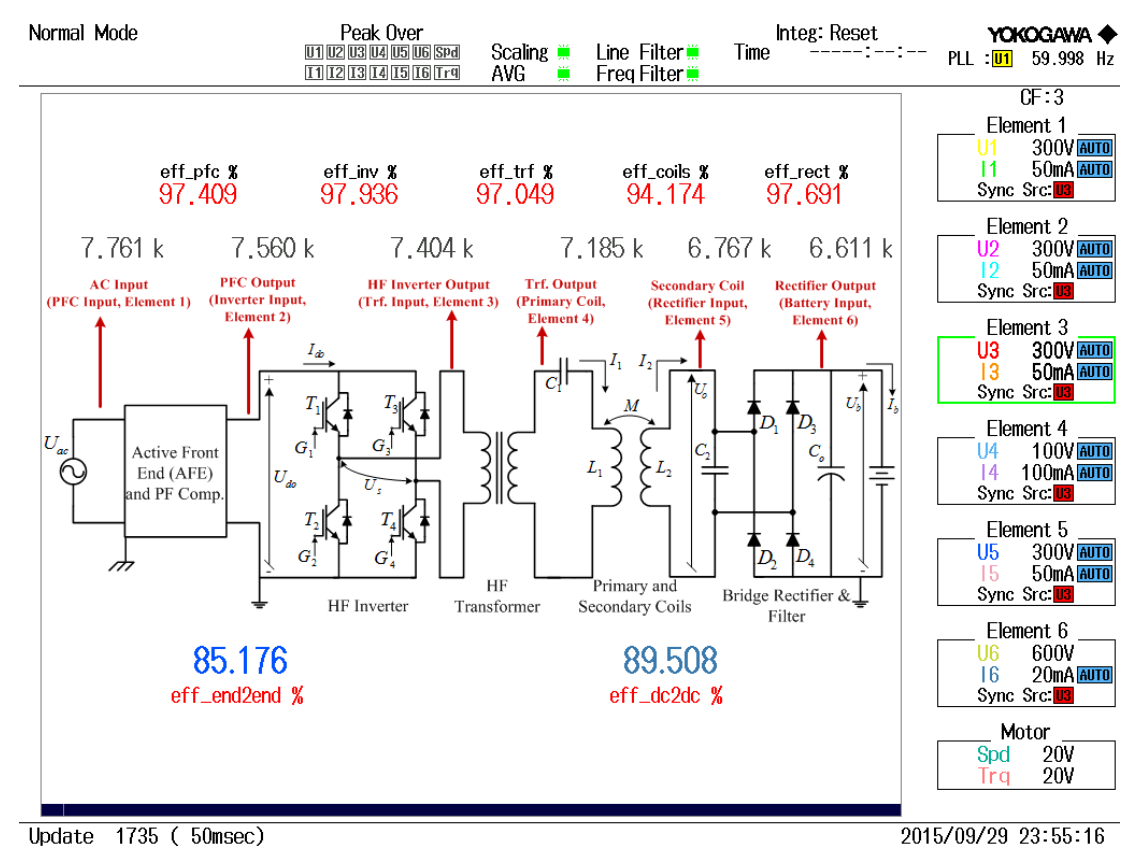

Figure 13. Toyota RAV4 EV test results: Power flow and efficiency across 5 power conversion stages.

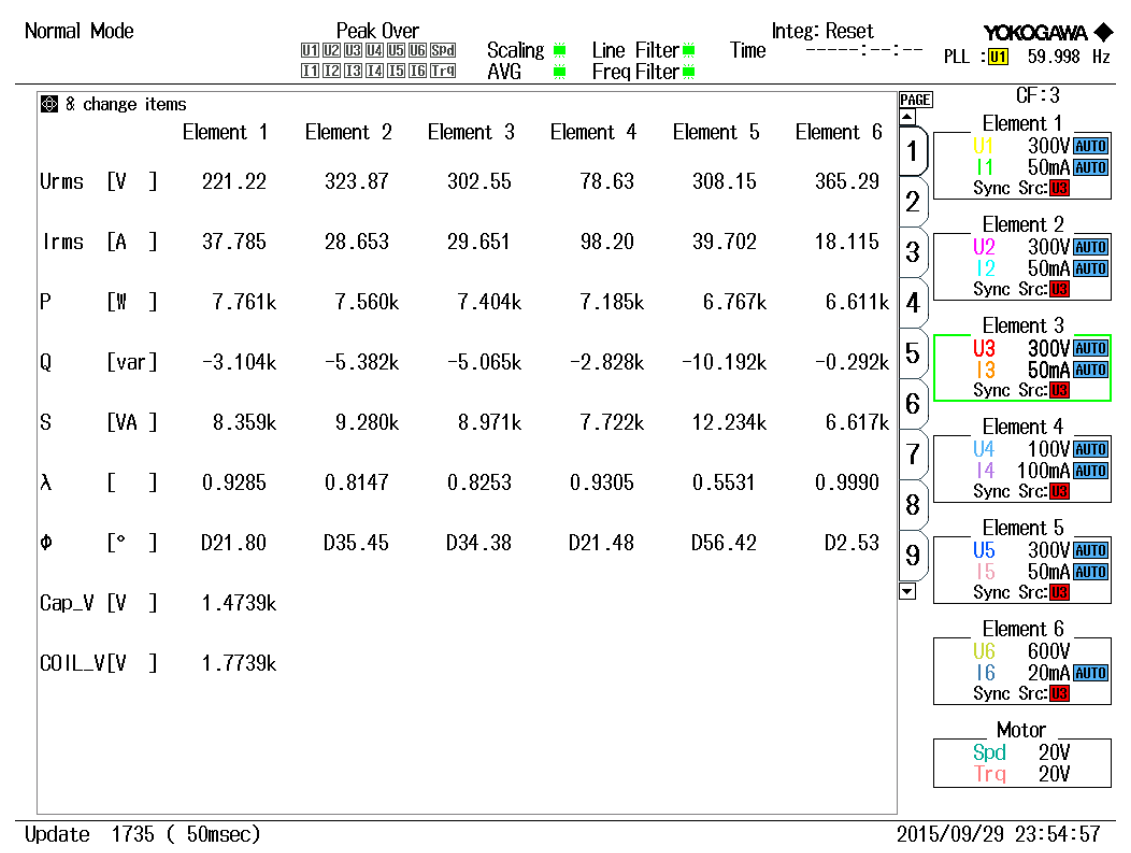

Figure 14. Electrical Test results across all power conversion stages as well as the primary coil and tuning capacitor voltages. 


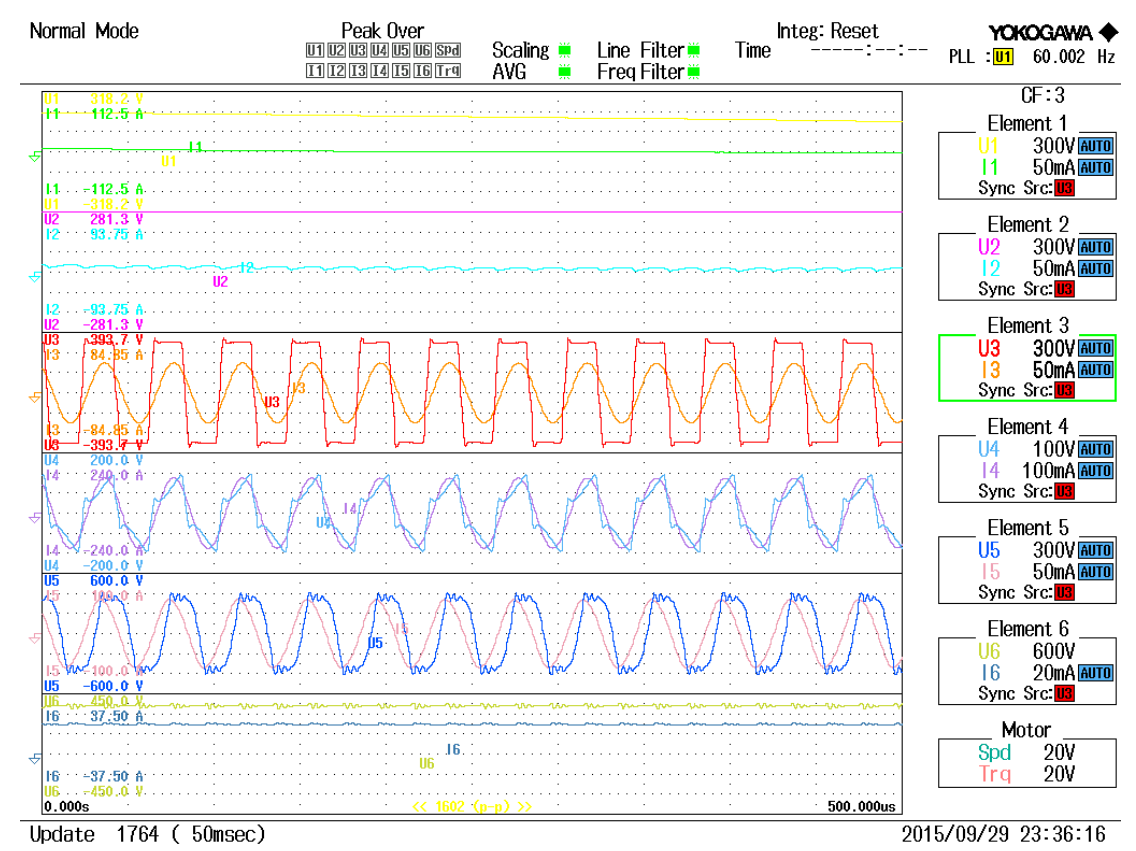

Figure 15. Operational waveforms for high frequency elements ( inverter, transformer, coupling coils).

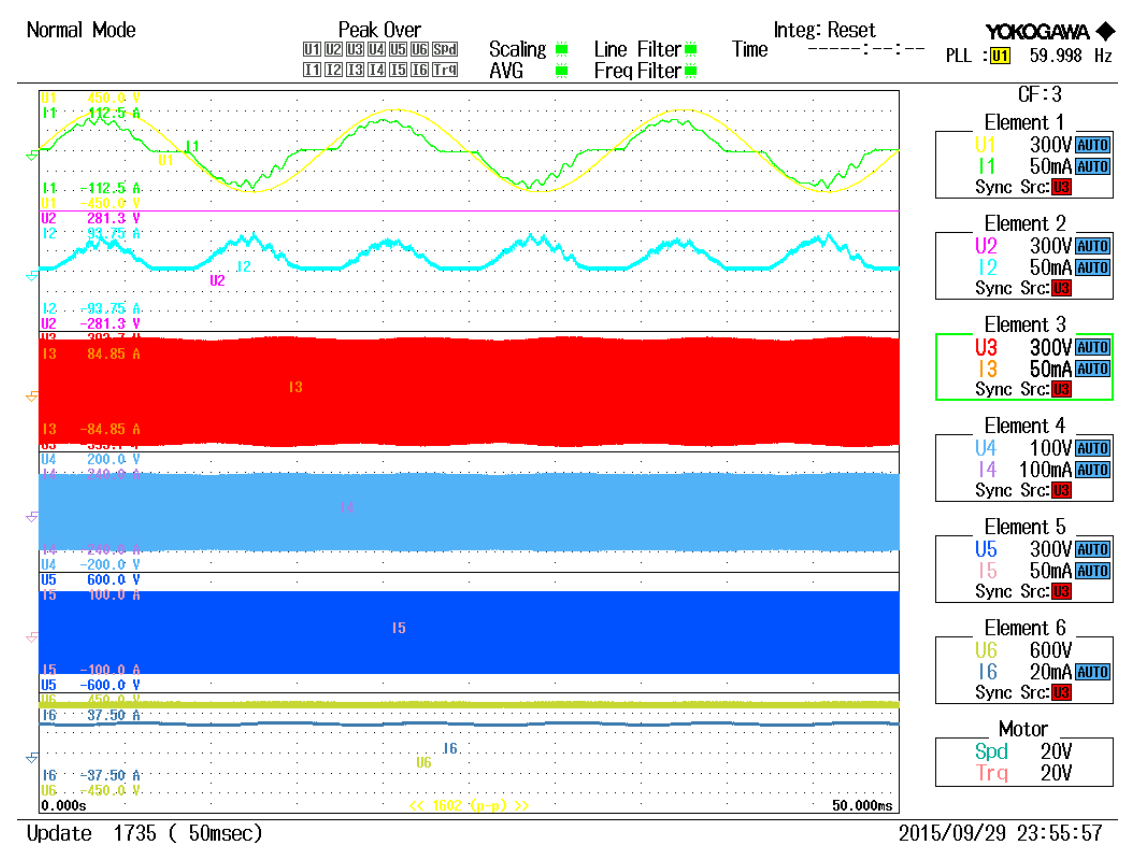

Figure 18. Operational waveforms for low frequency elements (AC grid input, DC link, vehicle battery). 
Based on the test results given in Figure 13, team identified that all of the power conversion stages are at least $97 \%$ or more efficient except the coil-to-coil efficiency. ORNL evaluated that the reduced coil-to-coil efficiency is due to the dimensional difference in primary and secondary coils. On vehicle side, initially, team used a secondary coil that is shorther by 2 inches from each side which reduces the coupling and the efficiency. According to SAE J2954 TIR definition, unmatched coils are interoperable coils and the efficiency expectation of systems with interoperable coils is $80 \%$ instead of $85 \%$. Due to the smaller size secondary coil, not all the field generated by primary coil can be captured by secondary. This results in higher fringe field emissions (Magnetic field). The matched and interoperable (unmatched) coils are given in Figure 19.
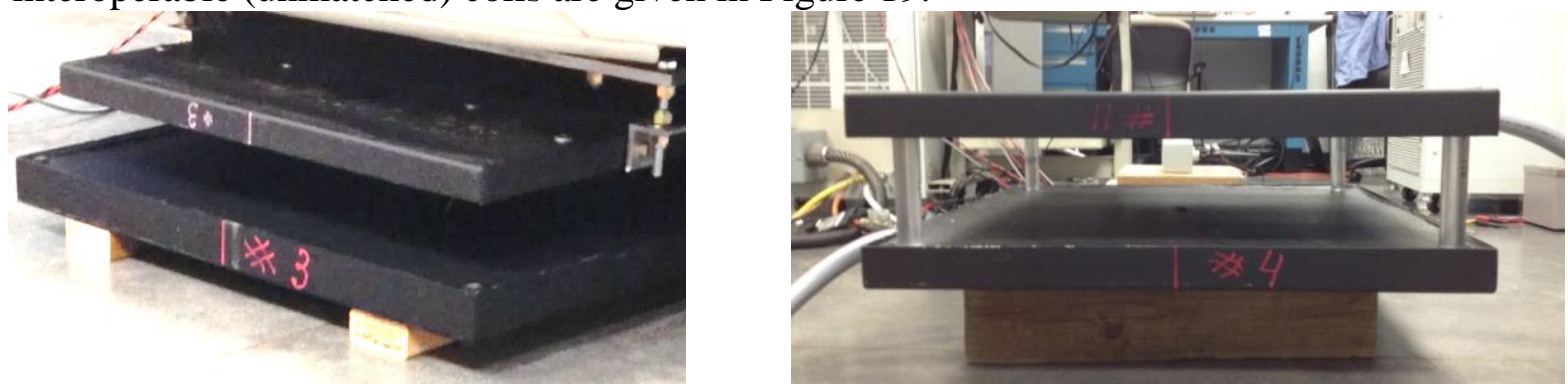

Figure 19. Unmatched (interoperable) coils on the left and matched coils on the right.

Toyota RAV4 EV laboratory test setup photograph is shown in Figure 20.

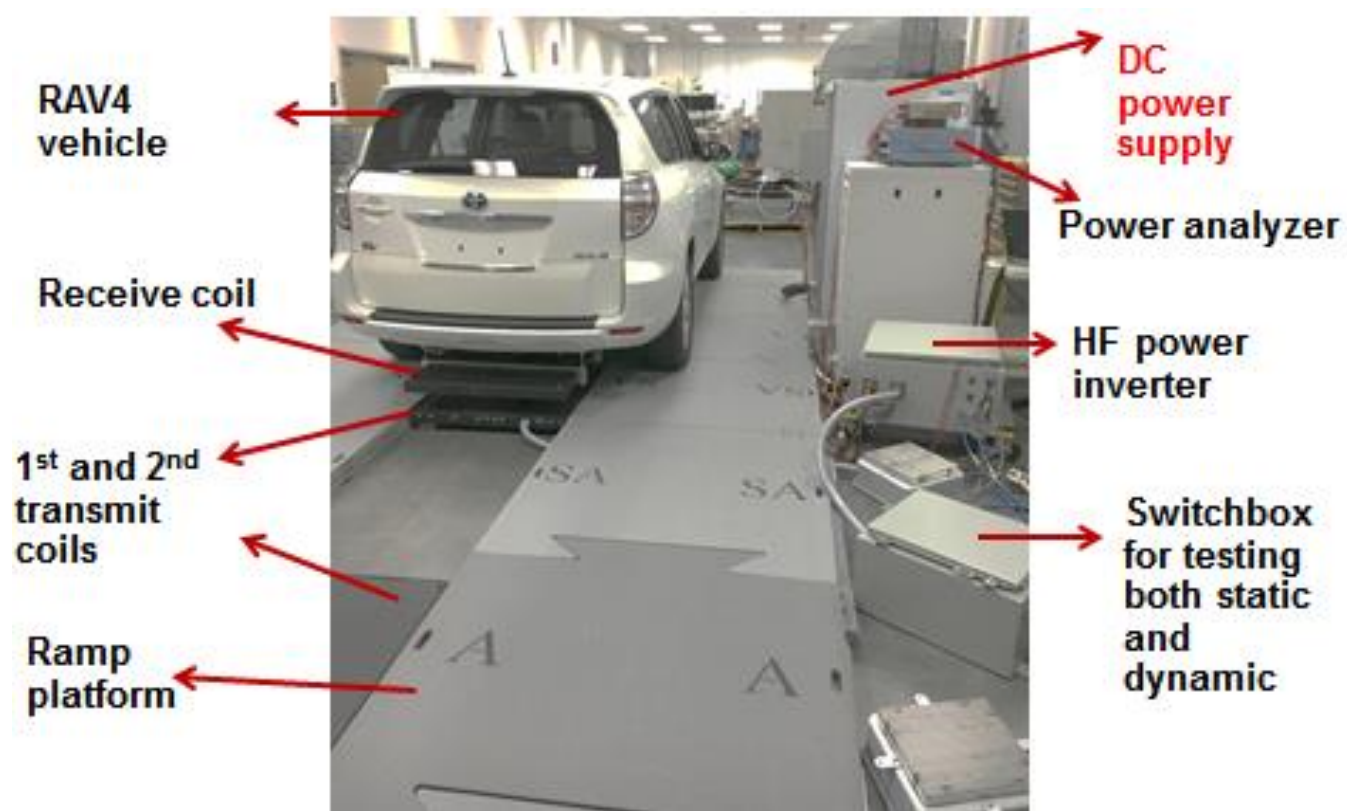

Figure 20. Laboratory test setup with RAV4 with matched coils.

While taking this step, team also eliminated the PFC stage, which was initially designed at $6.6 \mathrm{~kW}$, in order to identify the actual system maximum power, which was designed to be much higher than $6.6 \mathrm{~kW}$. When the tests are repeated, it is seen that the coil-to-coil efficiency with the matched coils are improved from $94.17 \%$ to $98.1 \%$. Efficiency of other stages such as vehicle side rectifier and grid side inverter efficiency also improved due to the 
reduced reactive power that they had to handle earlier with poor power factor. The updated test results are shown in Figure 21.

$$
\eta_{\text {INV }}=98.199 \% \quad \eta_{\text {TRF }}=98.599 \% \quad \eta_{\text {COILS }}=98.096 \% \quad \eta_{\text {RECT }}=99.403 \%
$$

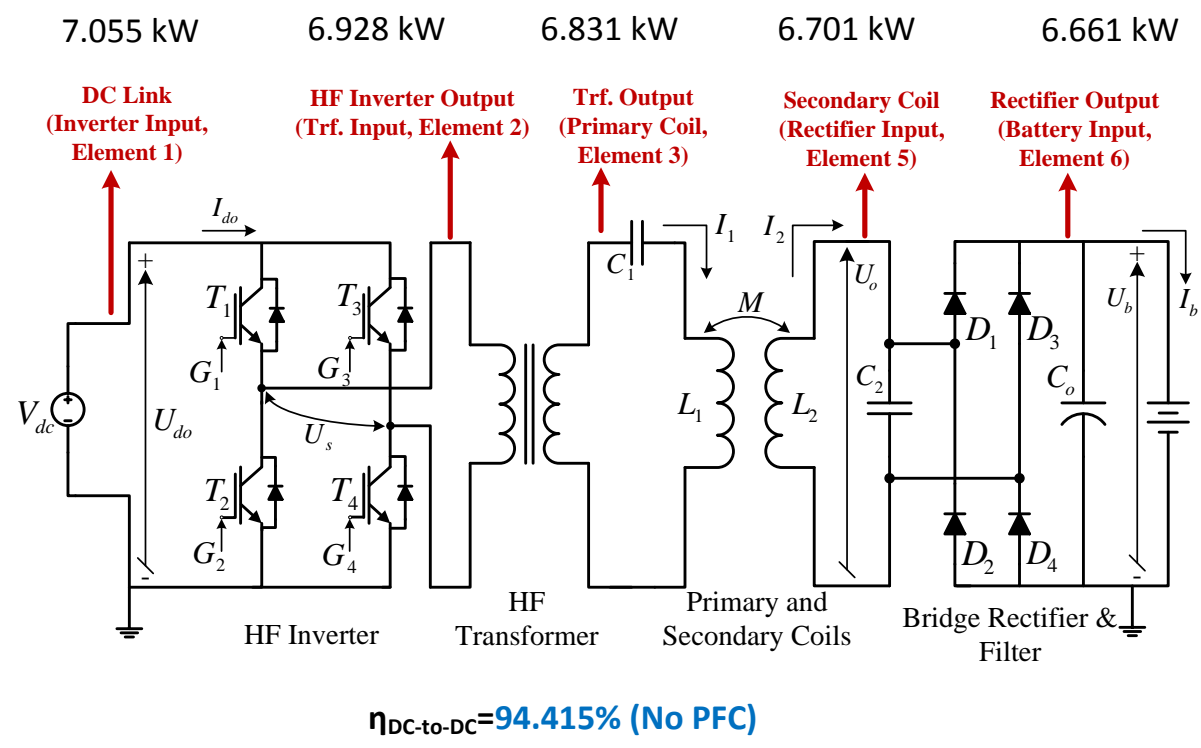

Figure 21. Updated test results with matched coils with improved efficiencies.

The team tested the WPT integrated Toyota RAV4 vehicle up to $\sim 20 \mathrm{~kW}$ power transfer after changing the resonant tuning configuration from series-parallel (SP) to series-series (SS). It is observed that SP tuning is more misalignment tolerant; however, is limited in the maximum power transfer. On the other hand, SS tuning provides a higher maximum power transfer; however, it requires a more precise alignment system since it is not very misalignment tolerant in direct battery connected systems. Test results for $20 \mathrm{~kW}$ power transfer are provided in Figure 22.

$$
\eta_{\text {INV }}=98.493 \% \quad \eta_{\text {TRF }}=99.048 \% \quad \eta_{\text {COILS }}=97.297 \% \quad \eta_{\text {RECT }}=99.431 \%
$$

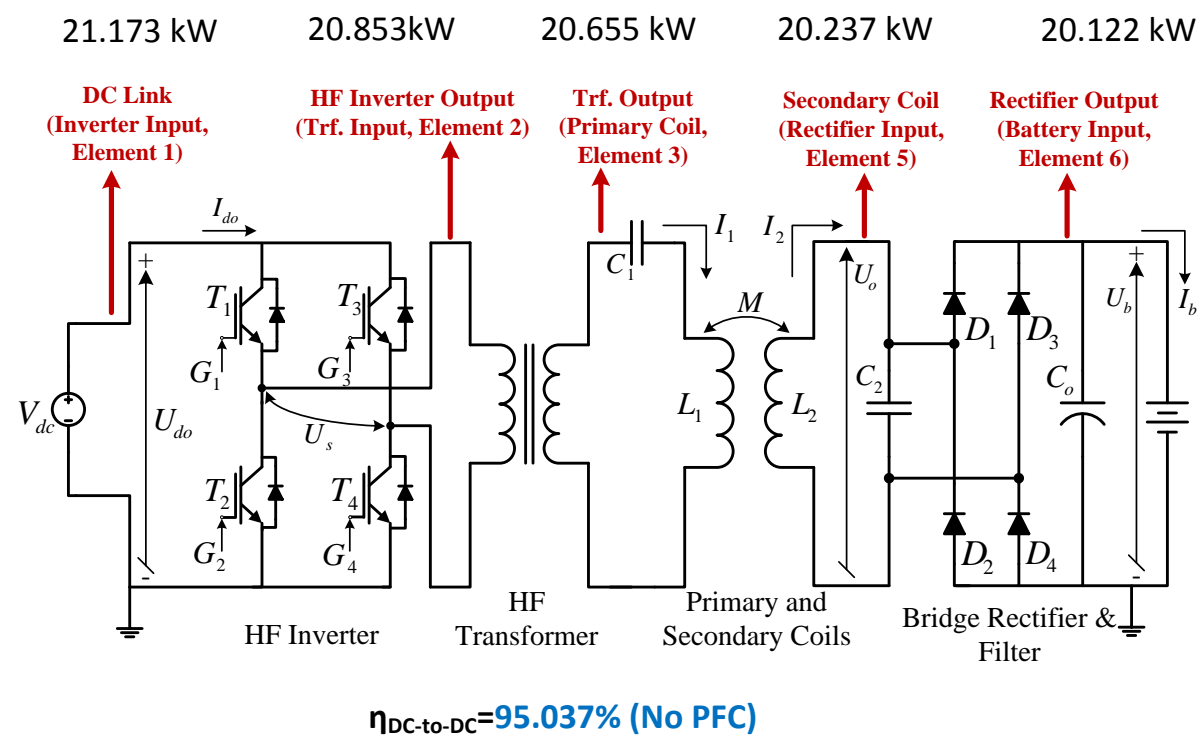

Figure 22. High power (20kW) testing for the Toyota RAV4. 
Using the same test setup show in Figure 20, team also demonstrated a dynamic (inmotion) wireless charging system for the Toyota RAV4 EV. In this setup, two transmit coils are connected series at the output of the system instead of a single coil. One coil length of space is left in between the coils. The layout of the track is given in Figure 23.

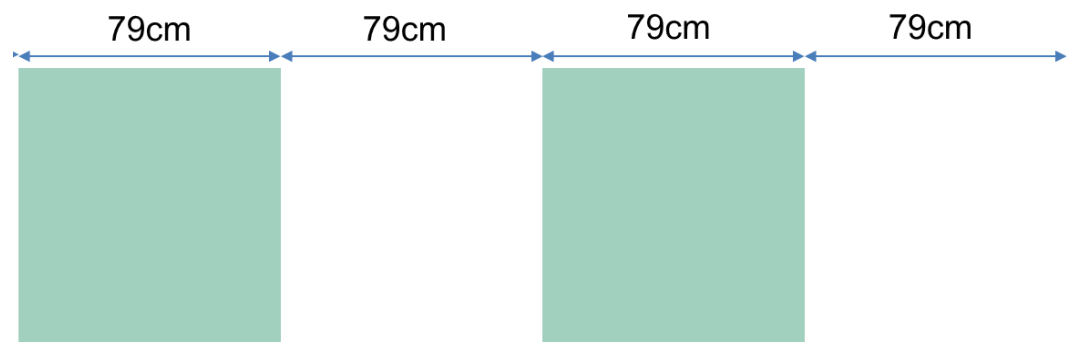

Figure 23. Track layout for the dynamic wireless charging setup with two coils (green squares).

The energy transfer with both the SS and SP tuned coils are investigated. The power variations with respect to the relative vehicle side coil position are given in Figure 24 for both the SS and SP tuned configurations. According to this figure, the ramp-up and fall-down skirts are wider in SP tuning configuration. Additionally, the peak power is higher. All these factors contribute to the higher energy transfer to the vehicle battery while the vehicle is in motion. Assuming 50 miles per hour constant travel speed and perfect lateral alignment, for SS tuning, 97.2 Watt-seconds (joules) are transferred to the vehicle battery by taking the time integral of the power vs. time curve. The same time integration for the power vs. time curve of the SP tuning configuration results in 281.08 Watt-seconds (joules). This corresponds to about 3 times higher energy transfer to the vehicle battery.

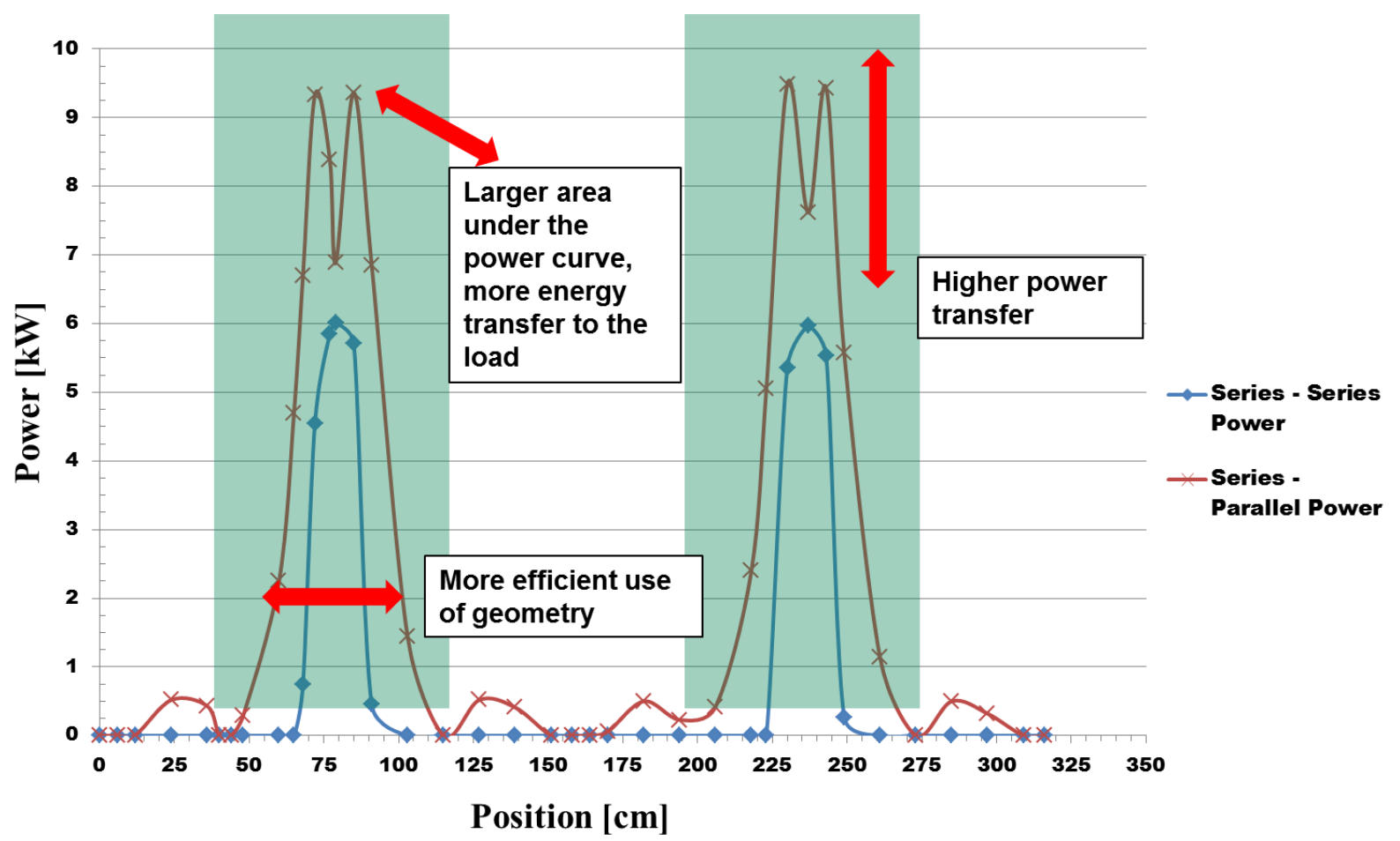

Figure 24. In-motion wireless charging test results: Tuning configuration comparisons. 


\section{Subject Inventions}

Granted and applied patents are listed below.

- ID-2250 - A Loosely Coupled Air Core Transformer with Improved Efficiency Operation, US Patent $\underline{8,310,202}$

- ID-2637 - Coupling Coil ac Resistance Minimization, US Patent Application 13/526,662

- ID-2638 - Regulation Control and Energy Management Strategy for Wireless Power Transfer, US Patent Application 13/484,404

- ID-2639 - WPT EVSE Installation and Validation Tool, US Patent Application 13/526,659

- ID-2667 - Wireless Power Transfer Electric Vehicle Supply Equipment Installation and Validation Tool, US Patent Application 13/544,058

- Vehicle to Wireless Power Transfer Coupling Coil Alignment Sensor, U.S. Patent no: $\underline{9,260,026}$

- ID-2768 - WPC Using Point of Load Controlled High Frequency Power Converters, US Patent Application 13/739,198

- ID-2813 - Off-Resonance Frequency Operation of Wireless Power Transfer US Patent Application $\underline{13 / 447,447}$

- ID-2956 - Buffering Energy Storage Systems for Reduced Grid and Battery Stress PCT patent application US13/027578

- ID-3196 - Overvoltage Protection System for Wireless Power Transfer Systems, US Patent\# 14/631,903.

\section{Commercialization Possibilities}

While still in the early stages of development, testing, and field use, wireless power transfer is receiving an increased interest both from consumers as well as the original equipment manufacturers. With competing technologies in the marketplace it is important to distinguish what differentiates one from the other. ORNL technology, developed in partnership with Toyota stands out with the high power and high efficiency capabilities since most of the developments are rated at $3.3 \mathrm{~kW}$ and their efficiency is around $85 \%$. Regarding the deployment, in general, the acceptance is relatively slow due to the lack of the standards in this field and application area of wireless power transfer systems. This initial project focused on the aftermarket outfitting of commercially available Toyota supplied vehicles and not the production vehicles. The systems will likely be integrated in production vehicles once the standards are available. Both ORNL and Toyota are the members of the SAE J2954 standards development committee on "Wireless Power Transfer for Light-Duty Plug-in / Electric Vehicles and Alignment Methodology." In May 2016, committee released the first Technical Information Report (TIR). Within the next two years, it is expected to have "Recommended Practices" document which will evolve from this initial TIR report. After another two years of development, testing, and evaluations, standards are expected to be finalized. Future commercialization of the technology will be affected by the standards development activities and how well the technology will develop to address the interoperability, electromagnetic compatibility, performance, safety, efficiency, and other vehicular integrational challenges. ORNL is taking necessary steps to make the technology 
more "commercialization ready" such as optimizing the size, weight, volume, and the cost of the grid side unit and the coupling coils and also optimizing the system operation in order to have a vehicle agnostic - interoperable system.

\section{Plans for Future Collaboration}

Both Toyota and ORNL enjoyed working together and appreciate the mutual learnings from this project. Both parties are looking forward for future collaboration opportunities.

\section{Conclusions}

This report summarizes progress, deep insights, and promotion of wireless charging system design technology led by ORNL in partnership with Toyota. The team has demonstrated cost savings for the WPT power electronics equipment and also improved coilto-coil efficiency and the overall end-to-end efficiency. ORNL demonstrated that a single grid side unit can be interoperable for three types of vehicles provided by Toyota. The recent progress allowed reaching over $20 \mathrm{~kW}$ wireless power transfer to the vehicle battery while exceeding 95\% dc-to-dc efficiency (excluding the PFC stage) over 160mm magnetic airgap. This WPT Level 4 charging power, charges a $20 \mathrm{kWh}$ battery pack in about an hour. ORNL shared the test data, findings, and integration challenges with Toyota. 